\title{
COUNSELLING OF PARENTS, ATTENDANTS, GUARDIANS IN DEALING OF PAEDIATIC SURGICAL PATIENTS
}

We the Paediatic Surgeons are to deal Paediatic patients of different ages with different types of problems. Majority of the problems are congenital in origin, may need multistaged operation, Post operative complications are more than adults. Childrens can not say about their problems upto a certain age. We are to remain more alert to detect problem \& progresses of their illness status. Due to natural affection Parents/ attendants remain anxious and tense. So we are to deal \& manage not only the Paediatic Surgical patients but also to manage their patients/attendants. We need to explain about the cause, nature and consequences of the illness the parents.

As stated above due to natural affection parents/ attendants do not want to accept the deterioration of illness status which increases the sufferings of the children's. Like that it becomes difficult for the parents to accept the possible complications of illness and or operations.

That's why it is necessary to increase our patience, to admire the anxiety of the parents. We need to explain in detail \& with patience. About nature, cause, progression, treatmentmodalities, possible complications, fate of the problem, any alternative regarding better facilities, possible cost, cost effectiveness i, e, every corner relating management of problems. It is better to explain the site of affection, nature, procedure of operation (if any) with sketch diagram and to use simple non medical terms so that parents can easily understand about problems, procedures complications (short term \& long term) and prognosis

\& fate of the problem so that they become mentally prepared to accept the consequences. Mothers are usually more concern and anxious regarding illness of their children. So we shall have to apply our wishdom in counseling mothers. Better not to explain $A$ to $Z$ her rather to explain every thing to father or other relatives who can tolerate.
Dealing of childhood tumour require involvement of multiple discipline. Better to explain about detict of disease in a clinic combined, information should be uniform. Now a days majority of the tumours have a good prognosis. So to keepin mind not to dishearten parents too much again not to inform over enthusiastically to develop their over expectation better not to hide the facts.

We are already overloaded due to over population, difficult to manage time to explain all these things but explanation is very necessary. Now it is time to think about appoint in social workers who will act as a bridge between parents and Paediatic Surgeons to avoid hitching and to run department smoothly which will bring better outcome..

Majority of the congenital anomalies have no definite cause, multifactorial in origin. We need to develop awareness among parents and obstetrician to ensure regular antenatal cheek up for early detection and interjection in selective cases. As consanguinity increases chances of cong. Anomalies we might counsel parents, relatives which will increase awareness for avoidance of consanguinities thus will be able to reduce incidence of cong anomalies \& ultimately to reduce load of Paediatic Surgeons \& sufferings of children's parents and paediatric surgical patients. As children's have different psychology than adults paediatic surgeons should be familiar with child psychology and behave friendly with their patients. Hopefully these guidelines wile help to bring better out come in paediatic surgery porches and will reduce misunderstand among parents / guardians and paediatic surgeon.

\footnotetext{
Prof. Kazi Habibur Rahman

Principal \& Project Director

Satkhira Medical College \& Hospital, Satkhira

E-mail:khabibpsbd@gmail.com
} 